\title{
KRISIS POLITIK DI KALIMANTAN BARAT 19508 SUATU PROSES MENUJU INTEGRASI KE DALAM REPUBLIK INDONESIA
}

\author{
THE 1950 POLITICAL CRISIS IN WEST KALIMANTAN: \\ A PROCESS TOWARDS THE INTEGRATION \\ INTO THE REPUBLIC OF INDONESIA
}

\author{
Mohammad Rikaz Prabowo', Aman', \\ 1,2 Magister Pendidikan Sejarah Universitas Negeri Yogyakarta \\ JL. Kolombo, Caturtunggal, Depok, Sleman, D.I. Yogyakarta \\ 1,2 e-mail: mohammadrikaz.2020@student.uny.ac.id, aman@uny.ac.id
}

DOI: 10.30959/patanjala.v13i2.796

\begin{abstract}
Abstrak
Penelitian ini bertujuan untuk mengetahui perjuangan integrasi wilayah Kalimantan Barat ke dalam Republik Indonesia (RI) pada tahun 1950 yang diwarnai krisis politik antara kubu republikan dengan pendukung Daerah Istimewa Kalimantan Barat (DIKB) yang mempertahankan federalisme bersama Republik Indonesia Serikat (RIS). Penelitian menggunakan metode sejarah melalui tahapan heuristik, kritik, interpretasi, dan historiografi. Hasil penelitian menunjukkan fakta bahwa krisis politik antara kedua kubu telah menyebabkan pemogokan massal pada bulan Maret 1950 di Pontianak yang berdampak luas pada bidang ekonomi se-Kalimantan Barat. Komisaris RIS dan DPR RIS datang untuk menengahi dan menyelesaikan krisis ini. Akan tetapi perubahan konstelasi politik terjadi cepat karena ditangkapnya Sultan Hamid II pada 5 April 1950. Jalannya pemerintahan DIKB yang tidak stabil mendorong penyerahan kekuasaan eksekutif kepada Pemerintah RIS pada 24 Mei 1950, dan secara resmi berintegrasi dalam RI setelah RIS dinyatakan dibubarkan pada 17 Agustus 1950.
\end{abstract}

Kata kunci: Daerah Istimewa Kalimantan Barat (DIKB), Sultan Hamid II, Republik Indonesia Serikat (RIS), Republik Indonesia (RI).

\begin{abstract}
The study aims to explore the struggle for integration of the West Kalimantan region into the Republic of Indonesia (RI) in 1950. The integration was marked by a political crisis between the republicans and the supporters of the Special Region of West Kalimantan (DIKB) who defended federalism with the United States of Indonesia (RIS). The study uses the historical method through the stages of heuristics, criticism, interpretation, and historiography. The results of the study indicate the fact that the political crisis between the two parts led to a mass strike in March 1950 in Pontianak. The strike had a wide impact on the economy throughout West Kalimantan. The Commissioners of the United States of Indonesia and the House of Representatives from the United States of Indonesia managed to mediate and resolve the crisis. However, changes in the political constellation occurred quickly due to the arrest of Sultan Hamid II on April 5, 1950. The unstable run of the Special Region of West Kalimantan government prompted the handover of executive power to the United States of Indonesia Government on May 24, 1950, and officially integrated into the Republic of Indonesia after the United States of Indonesia was declared disbanded on August 17, 1950.
\end{abstract}


Keywords: Special Region of West Kalimantan, Sultan Hamid II, United States of Indonesia, Republic of Indonesia.

\section{A. PENDAhULUAN}

Proklamasi kemerdekaan Republik Indonesia 17 Agustus 1945 menjadi babak baru dalam sejarah perjalanan bangsa. Indonesia berhasil lepas dari belenggu penjajahan dan bersiap memasuki masa depan dengan memerintah tanah airnya sendiri. Akan tetapi kehendak ini sesungguhnya mengalami banyak tantangan, salah satunya masalah kedaulatan wilayah negara. Masih banyak wilayah yang ketika itu ragu-ragu dan enggan menjadi bagian dari RI karena berbagai alasan.

Di Kalimantan Barat misalnya, kesultanan-kesultanan yang ada mengalami trauma berat pasca penjajahan Jepang yang merenggut banyak nyawa pemimpin dan kerabat mereka. Pemerintah RI dianggap belum memiliki pengalaman bernegara dan mampu menjamin keamanan serta kesejahteraan masyarakat, termasuk sistem feodal melalui pemerintahan swapraja yang ingin tetap dipertahankan. Di sisi lain, hubungan mereka dengan Belanda sebelum masuknya Jepang sudah terjalin cukup baik. Dengan begitu, ketika Netherlands Indies Civil Administration (NICA) di bawah pimpinan Dr. Van Der Zwall kembali hadir dan resmi berkuasa pada 22 Oktober 1945, 'mantan mitra' itu diterima dengan tangan terbuka.

Kondisi ini tentunya mendapatkan penolakan hebat dari pemuda republikan yang mendukung pemerintahan RI. Aksiaksi untuk menentang kehadiran kembali Belanda baik dengan gerakan massa maupun perlawanan terus berlangsung di seluruh penjuru Kalimantan Barat hingga tahun 1946 (Ahok et al., 1992: 53). Apabila ditarik lebih jauh, gerakangerakan penentangan Belanda untuk mencapai kemerdekaan telah muncul sebelum tahun 1942 di Kalimantan secara umum. Misalnya, pada tahun 1935 berdiri
Partai Indonesia Raya (Parindra) di ibukota Gubernemen Borneo, Banjarmasin yang diikuti dengan pendirian partai ini di kota lain (Wajidi, 2015: 19). Di Pontianak Parindra baru berdiri pada 1936 yang digawangi Raden Koempoel, Kepala Kantor Pos Pontianak dan Hadjarati guru Holland Inlandse School (Soedarto et al., 1978: 54). Akan tetapi saat Jepang berkuasa pada tahun 1942, seluruh aktivitas politik dilarang yang berimbas berakhirnya aktivitas Parindra di Borneo (Wajidi, 2015: 19). Itulah mengapa pasca proklamasi RI, gerakan-gerakan untuk menentang kembali Belanda seolah tinggal melanjutkan saja karena telah terkaderisasinya pemuda/tokoh yang sadar akan nasionalisme.

Gerakan ini akhirnya berkembang menjadi persaingan politik setelah munculnya organisasi Gabungan Persatuan Indonesia (GAPI) pimpinan dr. Mas Soedarso pada akhir 1946 dan Komite Naisonal Kalimantan Barat (KNKB) tahun 1949. Baik GAPI maupun KNKB menolak eksistensi Daerah Istimewa Kalimantan Barat (DIKB) yang dianggap bentukan Belanda pimpinan Sultan Hamid II, dan mendesak wilayah ini bergabung ke dalam RI (Soedarto, 1989: 99). Persaingan ini terus terjadi bahkan ketika DIKB telah menjadi bagian dalam Republik Indonesia Serikat (RIS) yang bersistem federalisme. Sistem ini oleh kalangan republikan dianggap sudah usang dan merupakan sisasisa pemerintahan feodal-kolonial. Sebaliknya, tokoh-tokoh DIKB yang didominasi para aristokrat menilai federalisme adalah sistem yang paling tepat diterapkan mengingat heterogenitas wilayah, sekaligus tetap mempertahankan corak pemerintahan swapraja.

Persaingan mencapai puncaknya pada tahun 1950, dengan terjadinya krisis politik di Pontianak. Terjadi pemogokan massal dan kelumpuhan ekonomi yang 
meluas ke daerah lain. Hal ini dikarenakan letak Pontianak yang strategis berada di muara Sungai Kapuas dan Sungai Landak sebagai pintu gerbang ke daerah-daerah pedalaman di Kalimantan Barat. Sebagai contoh, Ricklefs (2008) dalam Rahmayani (2013: 12) menyebutkan pada masa pendudukan Jepang, Pontianak yang menjadi kota penting bagi industri terpaksa terhenti. Hal itu memengaruhi perekonomian kota-kota di sepanjang aliran Sungai Kapuas dan Sungai Landak. Kota lain seperti Singkawang yang terkenal dengan industri keramik juga cukup bergantung pada Pontianak. Ini disebabkan keramik-keramik dari Singkawang banyak didistribusikan ke luar melalui pelabuhan Pontianak (Rahmayani, 2013: 15). Posisi strategis Pontianak dengan daerah-daerah lain telah menempatkan kota ini sebagai pusat perdagangan dan pusat Pemerintahan Karasidenan Borneo Barat oleh Belanda sejak dulu (Hasanudin, 2016: 204).

Peristiwa ini menarik untuk dikaji karena menjadi catatan sejarah yang belum banyak tersampaikan. Khazanah penulisan sejarah periode revolusi kemerdekaan di Kalimantan Barat cukup sedikit, sehingga membuat peneliti lainnya kurang memiliki gambaran seperti apa yang terjadi kala itu. Dengan demikian penelitian ini diharapkan dapat menambah kekurangan khazanah sejarah wilayah ini secara umum.

Kenyataan bahwa terdapat gerakangerakan politik untuk menentang berkuasanya kembali Belanda dan menolak federalisme perlu mendapat perhatian khusus. Hal ini guna mengubah pandangan dalam historiografi, bahwa periode ini dianggap hanya berisi perjuangan secara fisik atau bersenjata saja. Padahal perjuangan untuk menegakkan Negara Kesatuan Republik Indonesia (NKRI) juga melalui lobi-lobi dan diplomasi. Adanya krisis politik yang berdampak luas memengaruhi beberapa sektor di Kalimantan Barat pada periode itu layak menjadi suatu peristiwa besar. Penyelesaian yang diambil untuk mengakhiri krisis akan mengarah pada suatu kenyataan baru ketika nantinya Kalimantan Barat secara resmi berintegrasi bersama RI.

Apa yang terjadi di Kalimantan Barat pada periode ini, menggambarkan bagaimana proses pendewasaan Indonesia sebagai negara yang baru memeroleh kedaulatan mulai diuji. Wirawan dalam Bhakti dan Mengko (2018:5), menyebutkan proses pembentukan bangsa (nation building) yang masih dini akan memicu konflik horizontal. Para founding father menawarkan konsep bentuk negara yang menurut mereka paling ideal dan saling bersaing agar dapat diterapkan. Menurut Ni'matul Huda (2009: 49), RIS tidak dibentuk dengan landasan konsepsional yang matang. Dalam kenyataannya negara yang berbentuk federal ini bermula dari usaha Belanda untuk menghancurkan RI hasil proklamasi 17 Agustus 1945, sehingga banyak mendapatkan penolakan dari sejumlah tokoh-tokoh kemerdekaan.

Mengetahui bagaimana kondisi politik di Kalimantan Barat sebelum KMB tahun 1949 yang penuh persaingan antara kubu republikan dengan pro-federalisme, dapat menjadi pembuka untuk memahami bagaimana krisis politik ini akhirnya mencapai puncak di awal tahun 1950. Dengan demikian bahasan ini menjadi rumusan masalah yang pertama, kemudian dilanjutkan dengan membahas terjadinya krisis politik yang menyebabkan pemogokan massal dan kelumpuhan ekonomi. Pada rumusan masalah yang terakhir secara khusus akan membahas langkah atau upaya untuk menyelesaikan krisis politik yang mengarah pada integrasi Kalimantan Barat ke dalam RI.

Terdapat beberapa penelitian sebelumnya yang secara tidak langsung beririsan dengan topik yang diangkat oleh peneliti. Pertama, penelitian berjudul Sejarah Daerah Istimewa Kalimantan Barat (1946-1950) oleh Khamsyahurrahman, tahun 2015. Penelitian ini mengangkat secara khusus 
eksistensi DIKB mulai ketika hendak didirikan hingga akhirnya dibubarkan seiring bergabung dengan RI pada 1950 . Nilai lebih dari penelitian ini ialah memuat cukup lengkap struktur dan badan-badan organisasi DIKB serta daftar tokoh-tokoh yang bergabung di dalamnya. Kendati demikian, penelitian ini kurang menyampaikan dinamika politik yang terjadi pada periode tersebut, termasuk pertentangan-pertentangan antartokoh hingga menjadi suatu krisis politik.

Kedua, penelitian berjudul Regime Change and Ethnic Politics in Indonesia oleh Taufiq Tanasaldy, tahun 2014. Penelitian ini secara khusus mengangkat sejarah politik di tingkat lokal Kalimantan Barat dari masa kolonial hingga kontemporer. Salah satu bagian terpenting pada penelitian ini adalah bagian perkembangan politik di wilayah ini pada periode pasca Perang Dunia II hingga tahun 1950 yang memuat informasiinformasi dinamika sosial di sekitar Pontianak. Hanya saja, penelitian ini menekankan pada keterlibatan etnis Dayak sebagai kekuatan politik baru pada periode tersebut.

\section{B. METODE PENELITIAN}

Penelitian ini menggunakan metode sejarah melalui tahapan pengumpulan sumber-sumber/data (heuristik), kritik sumber (verifikasi), penafsiran pada sumber-sumber (interpretasi), dan penulisan sejarah (historiografi).

Salah satu sumber primer yang digunakan berasal dari catatan harian pelaku sejarah seperti karya $M$. Yanis yang telah dikemas dalam sebuah novel sejarah berjudul Djampea. Karya ini memiliki kelebihan karena mencatat peristiwaperistiwa yang terjadi secara kronologis dan penuh penghayatan. Bahkan penulis juga menuliskan koran-koran lokal yang meliput peristiwa-peristiwa tersebut. Sayangnya, koran lokal ini belum berhasil peneliti dapatkan. Hal ini mendorong penggunaan surat kabar yang terbit secara nasional melalui layanan daring
Perpustakaan Nasional RI dan layanan digitalisasi surat kabar berbahasa Belanda melalui Delpher (www.delpher.nl). Akan tetapi surat kabar yang digunakan hanya yang diterbitkan di Indonesia rentang waktu 1945-1950.

Adapun sumber-sumber sekunder yang digunakan berupa buku-buku dan hasil kajian yang terkait tentang RIS, revolusi kemerdekaan, dan sejarah sosial politik di Kalimantan Barat. Salah satunya buku Sejarah Revolusi Kemerdekaan 1945-1949 Daerah Kalimantan Barat oleh Pasifikus Ahok, Slamet Ismail, dan Wijoso Tjitrodarjono. Buku ini diterbitkan oleh Kanwil DEPDIKBUD RI Kalimantan Barat, penulis anggap kredibel karena ditulis oleh ahli dan menggunakan datadata yang terpercaya.

$$
\text { Langkah selanjutnya yakni }
$$

dilakukan kritik sumber baik secara eksternal dan internal. Fakta-fakta yang didapatkan dalam proses ini dimaknai dan ditempatkan secara kronologis dan tematis. Proses pemaknaan memerlukan pengetahuan yang mencukupi tentang tema penelitian yang sedang dikerjakan. Untuk itu diperlukan proses interpretasi. Seperti pada buku M. Yanis yang penulis sebutkan sebelumnya, meski dikemas dalam novel sejarah buku ini telah mendapatkan anotasi dari ahli. Asfar mengungkapkan M. Yanis memanfaatkan novel sebagai pencatat peristiwa sejarah dengan deskripsi yang menawan, ia meletakkan budaya sebagai gejala universal manusia, melontarkan kata balas (antwoord) terhadap kenyataan di dalam dan di luar diri penulis (Asfar, 2005: 96). Penjabaran fakta-fakta sejarah secara kronologis tanpa adanya suatu interpretasi akan menjadi sebuah karya kronik, bukan karya sejarah (Kanumuyoso, 2020: 44). Hal ini penting, agar dapat berlanjut dan dihasilkan penyusunan fakta-fakta yang komprehensif dalam proses historiografi.

$$
\text { Kanumuyoso (2020: 45-46), }
$$
menyebutkan penggunaan metodologi menyebabkan adanya pendekatan antara sejarah dengan ilmu-ilmu sosial lain. Hal ini dikarenakan setiap penggambaran 
terhadap gejala sejarah yang kompleks menuntut pendekatan yang memungkinkan seleksi fakta yang diperlukan. Untuk itu, penelitian ini menggunakan pendekatan politik yang menggambarkan bagaimana jalannya sejarah ditentukan kejadian politik, perang, diplomasi, dan tindakan tokoh politik. Oleh sebab itu sejarah konvensional adalah sejarah yang identik dengan politik (Abbas, 2014: 36).

Sejarah politik konvensional cenderung membahas peristiwa-peristiwa berdampak secara nasional. Berbeda dengan hal itu, pada penulisan ini digunakan kajian sejarah politik tingkat lokal. Peristiwa tingkat lokal tidak selalu merupakan hasil dari perkembangan politik di tingkat nasional. Akan tetapi dapat pula dimulai dari suatu kejadian yang menjadi besar sehingga berdampak secara lokal bahkan ke tingkat nasional (Kanumuyoso et al., 2020: 20-21).

Krisis Politik secara lebih jauh juga memengaruhi sektor perekonomian. Untuk itu pendekatan ekonomi juga digunakan dalam penulisan ini. Kanumuyoso (2020: 47), menyebutkan pendekatan ekonomi mengutamakan untuk melihat sejarah dari aspek hubungan pertukaran barang, pengakumulasian modal, pengorganisasian produksi, pelembagaan sistem moneter, dan sebagainya.

\section{HASIL DAN BAHASAN \\ 1. Kondisi Politik di Pontianak Sekitar KMB}

Perdebatan-perdebatan tentang bentuk negara federalis dan unitaris semakin gencar dibicarakan terkait dengan persiapan Konferensi Meja Bundar (KMB) di Den Haag Belanda. Kepala DIKB Sultan Hamid II, yang juga Ketua BFO memainkan peranan penting dalam lobilobi politik terhadap pemimpin republik. Ia berhasil mencapai kompromi dengan Mohammad Hatta dalam Konferensi Inter Indonesia (KII) di Yogyakarta pada 19-22 Juli 1949. Hasil kesepakatan tersebut yakni akan dibentuk RIS berdasarkan demokrasi dan federalisme. Pada KII kedua tanggal
30 Juli 1949 di Jakarta, bendera merah putih disepakati sebagai bendera RIS dan Presiden RIS nantinya juga dipilih bersama antara RI dan BFO (Putro, 2018: 40).

Sementara itu di Pontianak, organisasi GAPI telah mendapatkan suntikan tenaga baru pasca perombakan kepengurusan dan bebasnya sang pemimpin dr. Mas Soedarso. Hal ini berkat Kesepakatan Roem-Roijen pada 7 Mei 1949, dimana sebagai langkah awal perundingan antara Indonesia dengan Belanda, para tawanan republik yang sebelumnya ditahan telah dibebaskan (Agung, 1994: 84). Para tawanan sebagian besar belum diadili, dan tawanan di sini dalam artian tidak hanya personil Tentara Nasional Indonesia (TNI) atau militan republik, namun juga mereka yang menentang NICA (Amir, 2010: 352).

Di kemudian hari GAPI gencar melakukan desakan-desakan kepada Pemerintah DIKB agar mengizinkan pengibaran bendera sang dwiwarna Merah Putih (Putro, 2018: 40). Dalam KII silam juga telah disepakati Merah Putih sebagai bendera RIS. Pada 18 September 1949, Pemerintah DIKB mengizinkan pengibaran Merah Putih dengan syarat berdampingan dengan bendera Merah Putih Biru. Ukuran dan tingginya harus sama serta dikibarkan hanya pada hari-hari yang diperbolehkan (Het Nieuwsblad, 20 September 1949). Barulah pada 19 Oktober 1949 diizinkan mengibarkan bendera Merah Putih tanpa syarat apa pun seantero Kalimantan Barat terhitung mulai tanggal 24 Oktober 1949 (Yanis, 1998: 250).

Momentum ini tidak disia-siakan GAPI, dengan mengambil tempat di Lapangan Kebun Sayur, maka pada 24 Oktober 1949 diadakan upacara pengibaran Merah Putih yang dihadiri oleh berbagai elemen rakyat maupun organisasi politik dan kepemudaan. Juga hadir pada kesempatan itu organisasi Tionghoa yang turut memeriahkan. Sehingga diperkirakan upacara itu tidak kurang dihadiri oleh 3.000 warga masyarakat yang turut datang dengan membawa bendera Merah Putih 
(Ahok et al., 1992: 87). Aksi upacara ini menjadi ajang pembuktikan kepada pemerintah DIKB maupun NICA bahwa rakyat masih mendukung dan setia di belakang panji-panji kemerdekaan Indonesia.

Sementara itu di Den Haag Belanda, perundingan $\mathrm{KMB}$ untuk menentukan status Indonesia ke depan mulai dilaksanakan pada 23 Agustus 1949. Ada empat pihak yang saling berunding merumuskan solusi paling baik untuk Indonesia. Delegasi RI diketuai oleh Mohammad Hatta, Belanda dipimpin oleh Mr. Van Marseveen, BFO diwakili Sultan Hamid II, dan PBB dipimpin oleh Critchlay sebagai penengah (Utami, 2018: 101). Dalam sambutannya pada pembukaan KMB, Hamid menyebutkan sebagai negara yang bebas merdeka Indonesia akan mengambil tempat dalam deretan bangsa-bangsa merdeka dan mengharapkan pengertian dan kepercayaan seluruh dunia (Het Dagblad, 24 Agustus 1949).

Dalam kesempatan berbicara menyampaikan pandangannya dalam KMB, Sultan Hamid II tetap menyuarakan perlunya membawa Indonesia ke bentuk negara federal. Ia mengungkapkan alasan mengapa negara federal lebih cocok untuk Indonesia dan $\mathrm{BFO}$ perlu didirikan:

Sejak badan federal itu dilahirkan, maka ditujukan untuk tercapainya kemerdekaan Tanah Air kita, kemerdekaan bagi segenap bagian Tanah Air kita, dan untuk mencapai suatu persatuan yang dapat menjamin kemerdekaan baik bagi seluruhnya maupun untuk bagianbagiannya (Vinsensius, 2015: 24).

Sebenarnya Mohammad Hatta juga merupakan tokoh yang berpikiran Indonesia didesain dalam suatu federalisme. Menurutnya model negara seperti RIS dapat menata harmoni dalam suatu struktur yang federal, dengan desentralisasi sempurna hingga ke pelosok tanah air. Akan tetapi ia menekankan pada persatuan identitas yang muncul sebagai Bangsa Indonesia, tidak masalah Indonesia kelak diatur dalam suatu Eenheidsstaat (Negara Kesatuan) atau Bondstaat (Negara Serikat) (Mangunwijaya, 1999: 19 \& 23). Hatta juga menghargai dinamika dan keinginan rakyat akan negara Indonesia yang unitaris.

Pada 2 November 1949 perundingan KMB usai dengan menghasilkan keputusan, salah satunya Belanda mengakui RIS sebagai negara yang merdeka dan berdaulat. Akan tetapi penyerahan kedaulatan dari Belanda baru dapat dilaksanakan pada 27 Desember 1949 baik di Amsterdam maupun di Jakarta (Hatta, 2018: 222).

Di Kalimantan Barat sendiri, khususnya Pontianak, berita pengakuan kedaulatan disambut dengan ekspresi kebahagiaan. Akan tetapi, sebagian lain merasa kurang menerima karena bentuk federalisme yang disepakati, bukan negara unitaris/kesatuan. Pada 26 November 1949, GAPI mengadakan rapat untuk membahas isi dari perundingan KMB. Secara umum GAPI menerima isi dari perundingan sebagai suatu realita, namun dengan catatan bahwa mereka akan tetap mendukung negara kesatuan. GAPI juga menyatakan akan mengawal penyerahan kedaulatan Indonesia di Pontianak (Ahok et al., 1992: 87).

Keesokan harinya pada 27 November 1949, Sultan Hamid II sebagai salah satu delegasi dalam KMB telah kembali ke Pontianak. Ia disambut meriah oleh masyarakat yang bersuka cita atas suksesnya KMB (De Locomotief, 29 November 1949). Sultan Hamid II memainkan peranan penting dalam forum KMB. Kesediaan Belanda menyetujui penyerahan kedaulatan kepada RIS tidak terlepas dari keberhasilannya membujuk Ratu Juliana (Listiana et al., 2015: 5).

Untuk memantapkan perjuangan kaum republik, maka pada 26 November 1949 berdirilah organisasi Komite Nasional Kalimantan Barat (KNKB). Organisasi ini dikenal sebagai pendukung 
kuat unitarisme/kesatuan sebagai bentuk Negara Indonesia. KNKB berjuang dengan melakukan lobi-lobi politik yang bertujuan mengintegrasikan DIKB dalam RI ke depannya (Soedarto, 1989: 225).

KNKB mendapatkan dukungan dari berbagai elemen masyarakat/suku di Kalimantan Barat. Organisasi ini diketuai oleh Tan Husni Abdullah dan Sabam Hendrik Marpaung sebagai sekretarisnya. Tokoh-tokoh lain yang sebelumnya tergabung dalam PRI maupun GAPI seperti M. Nazir Effendi, Munzirin A.S, Burhan Ibrahim, dan A.S Djampi juga tergabung dalam KNKB (Tanasaldy, 2014: 96).

Menjelang penyerahan kedaulatan sebagaimana kesepakatan dalam KMB, unsur-unsur politik di Kalimantan Barat mulai memikirkan perlunya kehadiran pasukan TNI di wilayah ini untuk penjagaan keamanan. Unsur politik itu di antaranya adalah dari Partai Masyumi, mendesak GAPI dengan mosi agar pengiriman pasukan TNI segera terlaksana. Mosi itu kemudian dipertimbangkan oleh GAPI (Java Bode, 26 Desember 1949).

Pada 25 Desember 1949 atas nama KNKB, Sabam Hendrik Marpaung pergi ke Jakarta untuk meminta masuknya TNI ke Kalimantan Barat agar tidak terjadi kekosongan kekuatan pertahanan apabila Koninklijk Nederlandsch Indies Leger (KNIL) nantinya dibubarkan setelah penyerahan kedaulatan. TNI akan masuk ke Kalimantan Barat sebagai unsur utama dalam Angkatan Perang Republik Indonesia Serikat (APRIS) dimana nantinya akan dibuka kesempatan bagi tentara bumiputera eks-KNIL maupun pejuang dari badan-badan perjuangan untuk masuk ke dalam APRIS. Tepat pada 27 Desember 1949 diadakanlah upacara penyerahan kedaulatan RIS di bekas rumah residen Kalimantan Barat (Ahok et al., 1992: 87). Hal ini luput dari pantauan Sultan Hamid II yang telah kembali berangkat ke Belanda untuk menghadiri upacara penyerahan kedaulatan (Nieuwe Courant, 24 Desember 1949).

\section{Terjadinya Krisis Politik di Kalimantan Barat Tahun 1950}

Krisis politik yang terjadi pada tahun 1950 berawal dari semangat kaum republik yang tetap berkeinginan memperjuangkan Kalimantan Barat menjadi bagian RI. Misi itu belum tercapai hingga penyerahan kedaulatan 27 Desember 1949. Hal ini dapat dirunut pada keberadaan organisasi politik pro-RI yang masih tetap eksis pasca KMB, yakni GAPI dan KNKB. Soal tujuan perjuangan keduanya juga sama, menuntut DIKB bergabung dalam RI.

Salah satu pekerjaan rumah yang menjadi kekhawatiran seluruh lapisan masyarakat pasca KMB ialah persoalan keamanan. GAPI dan KNKB yang berpikiran selaras dengan Pemerintah RI, berpendapat bahwa sebagai tindak lanjut dari KII dan KMB maka tentara APRIS yang akan dibentuk haruslah intinya berasal dari TNI (Leirissa, 2006: 309). Hal ini juga sesuai dengan aturan Pasal 181 ayat (1) Konstitusi RIS dimana urusan pertahanan tetap dipegang oleh Pemerintah Federal RIS (D. Utami, 2004: 226).

Di wilayah Kalimantan Barat, perjuangan-perjuangan fisik membela kemerdekaan sebenarnya dilakukan oleh badan-badan perjuangan atau militan pro republik, bukan TNI (Ahok et al., 1992: 59). Kehadiran TNI harus disegerakan, bila tidak pembentukan APRIS di wilayah ini intinya akan berasal dari tentara eks-KNIL. Hal ini akan menyulitkan perjuangan kaum republikan dalam mengintegrasikan Kalimantan Barat ke dalam RI.

Pada 1 Januari 1950, TNI telah membuka markasnya di Pontianak dengan diiringi upacara penaikan bendera Merah Putih oleh beberapa organisasi pemuda dan kepanduan seperti Angkatan Pemuda Indonesia (API) dan Pelajar Islam Indonesia (PII). Keesokan hari, Komando Subteritorial dan Pasukan Kalimantan Barat mengeluarkan Pengumuman Nomor 1 tanggal 2 Januari 1950 yang ditandatangani oleh Mayor Suharsono tentang pemberian kesempatan pada pasukan gerilya maupun kelaskaran untuk 
mendaftarkan diri menjadi prajurit (Ahok et al., 1992: $272 \&$ 277).

Masuknya TNI di Kalimantan Barat ditanggapi berbeda oleh berbagai kalangan sehingga menjadi pembuka krisis politik di Pontianak. Menurut Kepala DIKB Sultan Hamid II, kedatangan TNI bukanlah suatu hal yang mendesak di wilayahnya terkait dengan hal keamanan. Ditambah pasukan yang telah ada seperti KNIL dan Tentara Federal DIKB belum dilakukan reorganisasi. Ia telah berkomunikasi kepada Menteri Pertahanan Sri Sultan Hamengkubuwono IX agar penyelesaian masalah pengiriman TNI itu menunggu dirinya pulang dahulu dari Belanda (Persadja, 1955: 59).

Dalam buku Tanjungpura Berjuang: Sejarah Kodam XII Tanjungpura, disebutkan terdapat suatu tendensi bahwa Sultan Hamid II menolak kedatangan TNI di wilayahnya. Kepada Mayor Suharsono yang juga turut mendarat bersama Letkol Sukanda Bratamanggala, Sultan Hamid II mengungkapkan bahwa ia menerima peleburan KNIL dan Tentara Federal ke dalam APRIS tetapi menolak kedatangan TNI di wilayahnya untuk turut dilebur. Menurutnya keberadaan eks-KNIL dan Tentara Federal yang juga akan melebur ke APRIS sudah cukup kuat untuk menjaga keamanan (Staf Semdam XII, 1970: 135).

Pola-pola penolakan kehadiran TNI sebagai pasukan inti untuk membentuk APRIS ini sebenarnya juga terjadi di wilayah lain kala itu. Setidaknya Peristiwa APRA di Bandung pada 23 Januari 1950, disebabkan karena sikap Westerling dan ribuan tentara KL, KNIL, serta tentara federal yang tidak setuju dengan pembentukan APRIS. Begitu pula dengan Peristiwa Andi Aziz (April 1950) di Makassar, menuntut agar hanya eks-KNIL yang dijadikan pasukan APRIS. Sedangkan di Ambon pada April 1950 justru lebih rumit dan berlarut. Selain menolak kedatangan TNI, juga mendeklarasikan pendirian Republik Maluku Selatan (RMS) dan memisahkan diri dari Indonesia (Bhakti \& Mengko, 2018: 54-55).

Masalah pengiriman TNI ini akhirnya menjadi pembicaraan di Kabinet RIS. Kolonel T.B Simatupang (Kepala Staf APRIS) mengungkapkan pasca keberatan Sultan Hamid II tersebut, TNI sempat menunda pengiriman pasukannya ke Kalimantan Barat. Akan tetapi setelah melalui proses sidang kabinet RIS, pengiriman TNI ke wilayah itu tetap diteruskan (Persadja, 1955: 103-105). Dengan demikian pengiriman TNI ini telah disetujui oleh Kabinet RIS yang memutuskan masalah dislokasi pasukan merupakan kewenangan Kementerian Pertahanan. Bukan semata-mata keputusan Sultan Hamengkubuwono IX sendiri. Selain itu, berdasarkan Pasal 182 ayat (2) Konstitusi RIS menyebutkan Pemerintah RIS dapat menunjuk Menteri Pertahanan sebagai Panglima Umum APRIS apabila dipandang perlu. Dengan demikian pemutusan masalah dislokasi berada di kewenangan Menteri Pertahanan sesungguhnya telah sesuai dengan konsitusi (D. Utami, 2004:226).

Datangnya pasukan TNI menuai pro dan kontra, golongan federalis yang masih kuat berkuasa mengecam gagasan ini namun mereka tidak dapat berbuat banyak. Di sisi lain beberapa tokoh DIKB mulai mengalihkan dukungan pada RI, di antaranya A.F Korak dan J.C Oevaang Oeray, keduanya anggota Badan Pemerintahan Harian (BPH), yang bertugas membantu tugas-tugas harian Pemerintah DIKB. Keduanya adalah tokoh Partai Persatuan Dayak (PPD) (Aju, 2017: 24).

Beberapa hari sebelumya pada 5 Januari 1950, KNKB mengadakan rapat dengan menghasilkan dua keputusan. Pertama, mencalonkan dr. Soedarso sebagai Kepala DIKB yang sejak 27 Desember 1949 dijalankan secara acting oleh Mahsyur Rifai. Ia ditetapkan sebagai acting karena Sultan Hamid II telah ditetapkan sebagai Menteri Negara RIS. Kedua, memprotes tindakan penangkapan 
16 pemuka masyarakat Ngabang pada tanggal 26 Desember 1949 tanpa alasan yang jelas. Keesokannya pada tanggal 6 Januari 1950 GAPI juga mengadakan rapat untuk menggagas diadakannya pemilihan umum untuk menentukan susunan Dewan Kalimantan Barat (DKB) yang baru. Sementara itu GAPI berencana untuk membubarkan diri dan menyerahkan perjuangan sepenuhnya kepada KNKB karena banyaknya kesamaan anggota (Usman, 2018: 88).

DKB melakukan sidang perdana dengan pembahasan pemilihan anggota baru pada 11 Januari 1950. Sidang diwarnai aksi demonstrasi KNKB dengan pengerahan massa. Pimpinan aksi, Sabam Hendrik Marpaung dan Uray Bawadi menuntut dibubarkannya DIKB dan bergabung dengan RI serta menerima masuknya TNI. Demonstrasi ini memang telah diprediksi akan terjadi. Sultan Hamid II kemudian menemui massa dan meyakinkan demonstran untuk tenang. Ia berjanji akan menanggapi tuntutan soal pemilu anggota DKB yang lebih demokratis.

Seusai massa demonstran bubar, sidang kembali dilanjutkan dengan berhasil memutuskan Masyhur Rifai meneruskan jabatan Pelaksana Sementara (acting) Kepala Daerah selama belum adanya keputusan berdasarkan pemilu baru (Java Bode, 12 Januari 1950). Posisi ini merupakan suatu hal yang cukup membingungkan, sebab Sultan Hamid II yang telah terpilih menjadi Menteri Negara RIS tidak meletakkan jabatannya sehingga terjadi dualisme jabatan. Di sisi lain ia tidak dapat melaksanakan tugasnya sebagai Kepala DIKB secara efektif karena sebagai menteri harus berada di Jakarta.

Krisis politik di Kalimantan Barat akhirnya mendorong Perdana Menteri Mohammad Hatta bersama rombongan di antaranya Menteri Dalam Negeri, Ide Anak Agung Gede Agung mengunjungi Pontianak pada 12 Januari 1950 (Het Nieuwsblad, 14 Januari 1950). Kedatangan Hatta ke Pontianak ini menjadi kesempatan kaum republikan untuk menyuarakan tuntutan mereka langsung. M. Nazir Effendy misalnya, ia mendesak agar DKB yang tidak representatif dan tidak demokratis dibubarkan serta segera dilaksanakan pemilihan umum. Hatta menanggapinya dengan tenang, menurutnya saat ini masih banyak yang harus dikerjakan dan disempurnakan dan kesemuanya itu butuh waktu. Sehingga ia mengharapkan massa untuk bersabar sampai pemilihan umum yang mereka inginkan dapat terselenggara (Yanis, 1998: 286).

Pada sore harinya ribuan massa berkumpul di Lapangan Kebon Sayur menghadiri rapat raksasa yang dipimpin oleh Menteri Dalam Negeri RIS, memberikan amanat atas nama Perdana Menteri. Dalam amanatnya, Ide Anak Agung kembali mengingatkan rakyat agar menerima apa yang telah digariskan oleh Pemerintah Pusat, sembari tetap bertindak tenang dan tentram menjaga daerahnya masing-masing. Pada 14 Januari 1950 Sultan Hamid II memutuskan untuk ikut bersama rombongan Perdana Menteri Mohammad Hatta ke Jakarta (Ahok et al., 1992: 88). Seperti diketahui, Sultan Hamid II merupakan Menteri Negara, yang diberikan tugas untuk merancang lambang negara. Turiman menyebutkan, lambang negara yang digunakan saat ini, Garuda Pancasila, merupakan hasil rancangannya yang ditetapkan oleh Dewan Menteri RIS tanggal 11 Februari 1950 dan disahkan Parlemen RIS pada 17 Februari 1950 (Turiman, 2013: 315).

Pasukan TNI sebagai unsur inti APRIS tepat mendarat di Pontianak pada 16 Januari 1950. Sebanyak 200 prajurit pimpinan Mayor Firmansyah mendarat dengan menumpang kapal KPM Kaimana. Kedatangan pasukan ini membawa kepercayaan diri lebih bagi republikan. Pasukan disambut dengan meriah oleh rakyat sepanjang jalan dari pelabuhan hingga ke tangsi (Ahok et al., 1992: 88). Di sisi lain warta berita juga melaporkan ada sebagian penduduk yang menaruh 
sedikit perhatian pada datangnya pasukan TNI (De Locomotief, 18 Januari 1950).

Pada 18 Januari 1950 Mayor Firmansyah sebagai Komandan Komando Subteritorium Militer I Kalimantan Barat mengumumkan bahwa persoalan keamanan khususnya di Kota Pontianak sepenuhnya telah berada di tangan APRIS. Keesokan harinya pada 19 Januari 1950 dikeluarkan lagi suatu pengumuman tentang pendaftaran diri pasukan-pasukan gerilya dan laskar-laskar republik. Kemudian pada 22 Januari 1950 kembali dilaksanakan rapat akbar yang bertujuan untuk mengenalkan TNI kepada rakyat di Lapangan Kebun Sayur (Yanis, 1998: 289). Kini masyarakat telah mengetahui kehadiran TNI yang bertugas untuk menjaga keamanan agar senantiasa tetap kondusif.

Desakan demi desakan terus dilancarkan oleh KNKB baik dengan sebuah mosi ataupun pengerahan massa untuk berdemonstrasi. Apalagi setelah diketahui beberapa negara-negara bagian maupun daerah otonom dalam RIS mulai melakukan pembahasan bergabung dengan RI. Feith (2007), mengungkapkan di akhir bulan Januari 1950 beberapa dewan legislatif negara/daerah seperti Jawa Timur, Madura, dan Jawa Tengah telah meloloskan resolusi untuk dapat bergabung ke dalam RI (Feith, 2007: 61). Hal ini dimungkinkan melalui Undang-undang Darurat Nomor 11 Tahun 1950 tentang Tata Cara Perubahan Susunan Kepengurusan RIS. UU ini menjadi dasar hukum bagi negara dan daerah untuk melakukan penggabungan (Sekretariat Negara Republik Indonesia, 1985: 42).

Desakan rakyat untuk bergabung ke RI tidak hanya terjadi di negara bagian/daerah di Jawa yang dikenal sebagai basis republikan. Bahkan, di Negara Indonesia Timur (NIT) yang merupakan negara bagian terbesar dalam RIS juga terjadi gerakan serupa. Pada 5-7 Februari 1950 Biro Pejuang Pengikut RI (BPPRI) berhasil mengadakan rapat akbar di Polombangkeng mendesak NIT bergabung pada RI. Dilanjutkan pada 23 Februari 1950 wakil BPPRI menuju Jawa menyampaikan sikap para pejuang dan republikan ke Pemerintah RIS (Amir, 2010: 354). Sementara itu DKB belum juga melaksanakan suatu pembicaraan ke arah menuju integrasi serupa. Sebagai usaha untuk terus menekan DIKB, KNKB mengadakan rapat raksasa untuk membuktikan besarnya dukungan rakyat akan penggabungan kepada RI. Rapat tersebut sedianya dilaksanakan pada 4 Maret 1950 di Lapangan Kebun Sayur (Yanis, 1998: 291).

Sayangnya, rapat ini dihalanghalangi oleh aparat dan menindak massa dengan kekuatan senjata (represif) hingga menyebabkan seorang massa terluka. Aksi penindakan itu diduga atas perintah Pelaksana Sementara Kepala DIKB (De Locomotief, 9 Maret 1950). Hal ini justru semakin memperbesar jurang antara kaum republikan dengan Pemerintah DIKB yang ingin tetap mempertahankan federalisme sehingga memperburuk krisis politik. Akibatnya, KNKB melakukan aksi pembalasan dengan mengadakan pemogokan massal seluruh pekerja dan buruh se-Pontianak pada 6 Maret 1950. Di luar dugaan, aparat justru membalasnya dengan penangkapan sejumlah tokoh politik seperti Sabam Hendrik Marpaung, M. Nazir Effendy, Munzirin AS, Burhan Ibrahim, AS Djampi, G.M. Affandi Rani dan beberapa pengurus KNKB. (Soedarto, 1989: 258).

Pemogokan umum ini menyebabkan kelumpuhan pada berbagai sektor ekonomi. Penduduk dalam dan luar kota yang menggantungkan hidupnya pada sistem distribusi terutama bahan pokok beras, mulai mengalami kesulitan sejak jaringan distribusi se-wilayah Kalimantan Barat yang berpangkal di Pontianak itu berhenti. Aktivitas bongkar muat di dermaga pelabuhan juga sepi. Supir angkutan yang bertugas mendistribusikan bahan-bahan pokok tidak ketinggalan ikut dalam aksi pemogokan dengan menolak 
mengangkut penumpang dan barang (Yanis, 1998: 292).

Imbauan dan anjuran KNKB ini diikuti tanpa paksaan dari para pekerja dan buruh, bukti bahwa organisasi ini memiliki pengaruh besar di Pontianak. Aksi pemogokan ini menyebabkan lumpuhnya kegiatan ekonomi yang berimbas pada kesulitan rakyat mendapatkan bahan pokok atau keperluan sehari-hari.

Penangkapan itu membuat pengurus KNKB tidak leluasa bergerak, hingga akhirnya keluar Pengumuman Nomor 2 tanggal 8 Maret 1950 yang menegaskan pemogokan terus berjalan sebelum adanya penjelasan resmi dan menuntut untuk segera dibebaskan rekan mereka yang ditahan. KNKB juga mendesak Komisaris RIS di Jakarta datang untuk ikut ambil bagian dalam penyelesaian krisis politik (Yanis, 1998: 291).

Esoknya pada 9 Maret $1950 \mathrm{KNKB}$ kembali mengeluarkan pengumuman akan membagikan beras kepada rakyat sembari tetap melaksanakan pemogokan. Kemudian pada 10 Maret 1950 KNKB kembali menegaskan pokok-pokok pendirian perjuangan mereka yang jadi tuntutan, yakni: Pertama, Kalimantan Barat bergabung ke RI dan mendapatkan otonomi seluasnya; Kedua, acting Kepala DIKB menyerahkan mandatnya; Ketiga, pucuk pimpinan daerah supaya dipegang oleh Komisaris RIS untuk sementara menunggu penggabungan ke RI (Yanis, 1998: 292).

\section{Upaya-upaya Menyelesaikan Krisis Politik dan Dampaknya}

Aksi pemogokan dan tuntutan yang dilancarkan oleh KNKB yang semakin hari semakin militan itu membawa keprihatinan Pemerintah Pusat RIS karena menyebabkan lumpuhnya perekonomian di Kalimantan Barat khususnya Pontianak. Menurut laporan, aksi mogok itu menyebabkan lumpuhnya komunitas bisnis dan tutupnya kantor pos, telegraf, dan telepon serta terhentinya transportasi publik. Bahkan warung-warung skala kecil juga memilih untuk tidak berjualan (Java Bode, 10 Maret 1950). Lebih jauh lagi sebagai dampak dari pemogokan dan alasan keamanan penerbangan, maskapai Garuda Indonesia Airways memutuskan untuk menghentikan pelayanannya yang kala itu lepas landas dengan pesawat amfibi dari Sungai Kapuas (Nieuwe Courant, 15 Maret 1950).

Akan tetapi demikianlah tujuan aksiaksi itu, agar permasalahan ini mendapatkan perhatian lebih dan Pemerintah RIS ambil bagian dalam penyelesaiannya. Kedatangan rombongan PM Mohammad Hatta pada 12 Januari 1950 yang mengupayakan kondusivitas politik nyatanya hanya menjadi solusi sementara.

Pada 12 Maret 1950 apa yang menjadi tuntutan KNKB akhirnya terbayar dengan kedatangan Komisaris Umum RIS Mr. Indra Kusuma dan M. Soeparto di Pontianak. Kedatangan rombongan komisaris ini bertujuan untuk menuntaskan masalah pemogokan di Kalimantan Barat dan menjadi penengah dalam krisis politik antara DIKB dengan KNKB. Atas perintah dari Komisaris Umum, dan demi kelancaran perundingan, maka tokoh-tokoh republik yang dijebloskan di Penjara Sungai Jawi kemudian dibebaskan (Andi \& Rahman, 2010: 35). Menurut Mr. Indra Kusuma, pemogokan yang berdampak luas ke seluruh Kalimantan Barat itu merupakan yang terbesar di Indonesia waktu itu (Soedarto, 1989: 260).

Secara terpisah pada 12 Maret 1950 itu pula, telah mendarat di Pontianak Komisi Fact Finding yang dibentuk oleh DPR-RIS. Misi ini diketuai oleh Mr. Lukman Wiriadinata yang bertugas untuk menilai keadaan di Kalimantan Barat dan mencatat fakta-fakta sebenarnya yang terjadi. Setelah melewati sejumlah penyelidikan dan mengadakan komunikasi ke berbagai pihak, komisi mengambil kesimpulan bahwa tidak ditemukan campur tangan TNI dalam kemelut di Kalimantan Barat termasuk dalam aksi pemogokan massal (Nugraha, 2012: 130). 
Aksi-aksi revolusioner seperti pemogokan massal berhasil membawa sejumlah pihak dari pusat baik unsur eksekutif (Komisaris Umum RIS) maupun unsur legislatif (DPR-RIS) berduyunduyun ke Pontianak menyelesaikan krisis politik yang ada. Secara paralel baik Komisaris Umum RIS dan DPR RIS menginisiasi pertemuan-pertemuan dengan menghadirkan perwakilan KNKB dan DIKB untuk menemukan solusi penyelesaian yang paling baik.

Pada 18 Maret 1950 berhasil dicapai persetujuan antara KNKB dan Pemerintah DIKB yang ditengahi oleh Komisaris Umum RIS, yakni pengumuman mengakhiri pemogokan (Usman, 2018: 96). Hari itu juga pemogokan massal usai dan secara berangsur kegiatan perekonomian kembali pulih. Hal ini juga tidak terlepas dari usaha Komisi Fact and Finding, dimana dr. Mas Soedarso terlibat sebagai sekretaris komisi dalam menengahi DIKB dan KNKB (Darmadi, 2017).

Komisaris Umum RIS juga mengumumkan dibentuknya suatu Badan Pertimbangan sebagai suatu lembaga transisi pemerintahan dan jalan tengah agar konflik antara Pemerintah DIKB dan KNKB berakhir. Badan Pertimbangan ini beranggotakan Sabam Hendrik Marpaung, Uray Bawadi, A. Mawardi Djafar, Mochtar Hadikusumo, dan Adenan (Usman, 2018: 97). Selanjutnya lewat Surat Keputusan Menteri Dalam Negeri RIS tanggal 20 Maret 1950, dibentuk Panitia Pemilihan Umum (PPU) DKB. Susunan PPU ini cukup seimbang berdasarkan keterwakilan baik dari republikan maupun kubu DIKB (Nugraha, 2012: 130).

Pada 5 April 1950 Sultan Hamid II ditangkap atas tuduhan keikutsertaannya dalam Pemberontakan APRA Bersama Westerling dan rencana penyerangan Dewan Menteri RIS pada 24 Januari 1950 (Nieuwsblad voor Indonesie, 6 April 1950). Kabar ini segera menjadi pembicaraan di kalangan republikan, membahas langkah selanjutnya yang harus ditempuh atas tertangkapnya Kepala DIKB itu. Hal ini semakin membawa ke arah kenyataan yang semakin rumit dan sulit untuk dipertahankannya eksistensi DIKB. Tertangkapnya Sultan Hamid II menyebabkan perubahan cepat konstelasi politik di Kalimantan Barat.

Secara de-facto Pemerintahan DIKB tidak pernah berjalan dengan baik, telah dibentuk juga Badan Pertimbangan sebagai lembaga transisi pemerintahan. Ditambah Sultan Hamid II semakin mustahil menjalankan tugasnya karena ditahan pihak berwenang. Maka atas dasar itu, pimpinan KNKB mengirim kawat kepada Pemerintah RIS menuntut agar DIKB dibubarkan. Tuntutan ini ditolak, namun berjanji akan segera mengirimkan seorang Residen untuk menjabat (Nugraha, 2012: 131).

Berkaca pada kondisi aktual di Kalimantan Barat dimana semakin gencarnya tuntutan untuk pembubaran DIKB yang terkulminasi dengan pemogokan umum. Maka, DPR-RIS pada 15 April 1950 melakukan voting dan menghasilkan mosi mendukung DIKB bergabung dengan RI (Feith, 2007: 65). Mosi disahkan dengan perbandingan lima puluh lawan satu suara secara aklamasi dan mengusulkan afiliasi Kalimantan Barat ke RI (De Locomotief, 18 April 1950).

Mosi pengambilan suara itu dalam hemat penulis pasti melibatkan perwakilan dari anggota Senat yang mewakili negara bagian/daerah. Sebab, sistem parlemen pada masa itu menganut sistem bikameral, kekuasaan (perundang-undangan) federal dilakukan oleh pemerintah bersama-sama DPR dan Senat khusus mengenai hubungan antara RIS dan daerah-daerah bagian (Widayati, 2015: 421). Pemerintah RIS pun kemudian merespon dengan mengangkat R. Budiarjo sebagai Residen mulai 18 April 1950, menggantikan Mahsyur Rifai (Nugraha, 2012: 131).

Ditangkapnya Sultan Hamid II menyebabkan Pemerintah DIKB kurang memiliki legitimasi politik. R. Budiarjo bukan memimpin atas nama Pemerintah DIKB, ia dikirim sebagai kepanjangan 
tangan pusat. R. Budiarjo diberikan kekuasaan-kekuasaan federal hingga terpilihnya Dewan yang baru dan pemilihan tentang bergabung atau tidaknya DIKB pada RI (Kalimantan Berdjuang, 31 Maret 1950). Cepat atau lambat R. Budiarjo juga akan kembali ditimpali dengan jabatan Kepala Daerah.

Pada dasarnya DKB siap menjalin kerjasama dengan Pemerintah RIS atas dasar federasi. Akan tetapi tekanan rakyat dan pergolakan politik terus menuntut dibubarkannya DIKB serta keadaan ekonomi yang tidak kunjung membaik. Maka pada pada 7 Mei 1950, lewat sebuah sidang akhirnya Badan Pemerintahan Harian (BPH) menyatakan pembubaran dirinya (Abubakar et al., 2019: 142). Seluruh kewenangan pemerintahan dan dewan eksekutif akan dilimpahkan ke pemerintahan RIS sesuai ketentuan konstitusi (Niuwe Courant, 12 Mei 1950).

Fungsi-fungsi eksekutif pada DIKB secara teknis dapat dikatakan sudah tidak eksis lagi. Pembubaran 7 Mei 1950 tersebut, dilandasi dua surat keputusan sidang, yakni Nomor 234/R dan 235/R. Isinya berturut-turut, BPH dan Pelaksana Sementara Kepala DIKB, menyerahkan segala hak dan kekuasaannya kepada Pemerintah RIS yang diwakili oleh seorang Pejabat yang berpangkat Residen. Lebih lanjut lagi mulai tanggal $10 \mathrm{Mei}$ 1950, DIKB yang berdiri berdasarkan Keputusan DKB Nomor 179/DW tertanggal 22 September 1947 dinyatakan tidak berlaku lagi (dihapuskan). Pada 24 Mei 1950 Menteri Dalam Negeri RIS kembali mengeluarkan Surat Keputusan No. B.Z.17/2/47, menetapkan bahwa segala hak dan kewajiban yang sudah tidak dapat dijalankan lagi oleh Pemerintah DIKB dan alat-alat perlengkapannya yang diserahkan oleh swapraja, untuk sementara dijalankan oleh seorang Residen berkedudukan di Pontianak (Aju, 2017: 71).

Dengan demikian Kalimantan Barat tinggal selangkah lagi agar bergabung ke dalam RI. Pemerintah RIS dan Pemerintah
RI sebenarnya merencanakan diadakannya suatu konferensi untuk membicarakan tentang pembentukan negara kesatuan yang dimulai pada 16 Mei 1950 (Java Bode, 10 Mei 1950). Konferensi menghasilkan komunike bersama antara PM. Mohammad Hatta mewakili RIS dan PM. Abdul Halim mewakili RI pada 19 Mei 1950 yang menyepakati pembentukan negara kesatuan (Nieuwe Courant, $20 \mathrm{Mei}$, 1950).

Di bidang keamanan, kondisi Kalimantan Barat yang mulai kondusif dari ketegangan politik berpengaruh positif pada reorganisasi tentara dalam rangka pembentukan APRIS. Sekitar pertengahan bulan Maret 1950, Komando Sub Teritorium Militer I Kalimantan Barat kembali diperkuat satu Kompi Pancasila pimpinan Kapten S. Harmojo dari Divisi Diponegoro (Jawa Tengah). Pada 9 April 1950 kembali diperkuat satu Batalyon Pagarruyung pimpinan Mayor Mustafa Kamal dari Sumatera Barat. Fusi tentara KNIL dan TNI dalam membentuk APRIS semakin menunjukkan perkembangan yang baik. Pada 7 Juni 1950, Komandan KNIL di Kalimantan Barat menyerahkan pasukannya untuk bergabung ke dalam APRIS, antara lain: satu kompi KNIL di Sintang, Ketapang, Sambas, dan Singkawang, serta 1 kompi tentara federal di Pontianak (Staf Semdam XII, 1970: 141).

Kalimantan Barat akhirnya resmi bergabung ke dalam RI seiring penghapusan RIS. Pada 17 Agustus 1950 di Jakarta, Presiden Sukarno memproklamasikan pengembalian bentuk Indonesia menjadi negara kesatuan. Presiden mengharapkan dengan kembalinya ke bentuk kesatuan diharapkan stabilitas dapat tercipta di Indonesia (Nieuwsblad voor Indonesie, 18 Agustus, 1950).

Pendirian DIKB sedari awal sebelum berdirinya RIS (1947), memang cukup kontroversial. Diiringi berbagai prokontra di lingkungan masyarakat maupun di pihak-pihak yang memiliki kekuatan 
politik. Masyarakat, memandang bahwa DIKB sebagai warisan pemerintahan kolonial yang tidak sesuai lagi dengan alam kemerdekaan yang telah dicapai. Sebaliknya, pihak raja-raja ingin tetap mempertahankan kekuasannya (Alqadrie \& Sastrowardoyo, 1984: 88).

Bubarnya DIKB merupakan salah satu contoh kegagalan Indonesia menerapkan sistem federalisme kala itu. Dari sisi perimbangan politik, kegagalan ini sebenarnya telah diprediksi sejak penetapan susunan Kabinet Hatta pada 20 Desember 1949 yang tetap didominasi oleh tokoh republik. Sementara dari sisi keamanan, negara-negara bagian atau daerah seperti Negara Pasundan diklaim tidak dapat menjamin keamanan dan ketentraman rakyat (Rinardi, 2012: 183184). Sehingga hal ini berpengaruh pada stabilitas nasional. Munculnya pemberontakan-pemberontakan seperti di Bandung, Makassar, Ambon, dan juga pemogokan umum di Pontianak menjadi bukti konkrit gagalnya negara bagian/daerah menciptakan kondusivitas.

\section{PENUTUP}

Dari pembahasan di atas dapat ditarik sejumlah kesimpulan. Pertama, di sekitar KMB friksi antara kaum republikan dalam GAPI dengan kelompok federalis di DIKB berhasil direduksi. GAPI menerima isi KMB sebagai realita perjuangan dan tetap memperjuangkan agar Kalimantan Barat berintegrasi ke RI. Untuk lebih memantapkan misi, dibentuk Komite Nasional Kalimantan Barat (KNKB). Sebagai usaha pertamanya, utusan KNKB berangkat ke Jakarta pada 25 Desember 1949 untuk meminta TNI segera mengambil alih keamanan di wilayah ini.

Kedua, kedatangan TNI untuk mengambil alih keamanan memicu krisis politik. Kepala DIKB merasa kehadiran TNI belum diperlukan karena pasukan KNIL yang ada sudah cukup. Akibatnya terjadi demonstrasi yang menuntut diterimanya TNI dan dibubarkannya DIKB. Puncak krisis politik terjadi pada 4
Maret 1950, aparat menangkap pemimpin KNKB dan menindak represif massa yang hendak mengadakan rapat raksasa dan menuntut pembubaran DIKB. Akibatnya, pada 6 Maret 1950 KNKB mengajak mogok massal pekerja yang diikuti oleh rakyat. Pemogokan ini menyebabkan lumpuhnya aktivitas ekonomi.

Ketiga, upaya yang ditempuh untuk menyelesaikan krisis politik secara umum dilakukan melalui perundingan. Lewat mediasi dari Komisaris Umum RIS dan DPR-RIS, pada 18 Maret 1950, KNKB dan DIKB setuju untuk mengakhiri pemogokan dan membentuk Badan Pertimbangan sebagai lembaga transisi pemerintahan dan jalan tengah mengakhiri konflik. Akan tetapi, ditangkapnya Sultan Hamid II pada 5 April 1950 mendorong perubahan konstelasi politik ke arah proses likuidasi DIKB. Pemerintah RIS mengirimkan R. Budiarjo untuk menjadi Residen Kalimantan Barat. Pada 7 Mei 1950 lewat surat 234/R dan 235/R, DIKB mengeluarkan keputusan bahwa Badan Pemeritahan Harian dan acting Kepala Daerah DIKB menyerahkan hak dan kekuasannya kepada Residen Kalimantan Barat, serta mulai tanggal 10 Mei 1950 DIKB dinyatakan dibubarkan. Kalimantan Barat resmi berintegrasi ke RI pada 17 Agustus 1950 seiring penghapusan RIS.

\section{DAFTAR SUMBER}

Abbas, I. (2014). Memahami Metodologi Sejarah Antara Teori dan Praktek *). In Jurnal ETNOHISTORI (Vol. 1, Issue 1). http:/garuda.ristekdikti.go.id/documents/ detail/848669

Abubakar, A., Krisdiana, R., Usman, S. D., Andi, U. F., Wibawa, M. A., \& Akbar, A. (2019). Menegakkan Kedaulatan dan Ketahanan Ekonomi: Bank Indonesia Dalam Pusaran Sejarah Kalimantan Barat (Nawiyanto (ed.)). BI Institute.

Agung, I. A. A. G. (1994). Pernyataan RumVan Roijen 7 Mei 1949. Yayasan Pustaka Nusatama-Sebelas Maret University Press. 
Ahok, P., Ismail, S., \& Tjitrodarjono, W. (1992). Sejarah Revolusi Kemerdekaan (1945 - 1949) Daerah Kalimantan Barat. Departemen Pendidikan dan Kebudayaan. https://pustaka.kebudayaan.kemdikbud.g o.id/index.php?p=show_detail\&id=1524 \&keywords=

Aju. (2017a). J.C. Oevaang Oeray: Dari Federasi ke NKRI. Derwati Press.

Aju. (2017b). Kalimantan Barat: Lintasan Sejarah dan Pembangunan dari Era Kolonial Belanda-Tahun 2013. Derwati Press.

Alqadrie, S. I., \& Sastrowardoyo, P. (1984). Sejarah Sosial Daerah Kotamadya Pontianak. Departemen Pendidikan dan Kebudayaan.

http://pustaka.kebudayaan.kemdikbud.go. id/index.php?p=show_detail\&id=2384\& keywords $=$ sejarah + sosial+kotamadya + po ntianak

Amir, M. (2010). Dari Federalis Ke Unitaris: Studi Kasus Sulawesi Selatan 1945-1950. Patanjala: Jurnal Penelitian Sejarah Dan Budaya, 2(2), 341. https://doi.org/10.30959/patanjala.v2i2.2 22

Andi, T. N., \& Rahman, R. (2010). Pemerintahan Kota Pontianak dari Sultan Sampai Walikota. Komunitas Lentera.

Anonim. (1947, Mei, 13). West-Borneo-Statuut Getekend. Het Dagblad, 4.

Anonim. (1949, Agustus, 24). Sultan Hamid II ter R.T.C: Indonesie iz Zwaar Ziek. Het Dagblad, 2.

Asfar, D. A. (2005). Citra Manusia Dalam Novel Sejarah Perjuangan Rakyat Kalimantan Barat Karya M. Yanis. Balai Bahasa Kalimantan Barat.

Bhakti, I. N., \& Mengko, D. M. (2018). Intelejen dan Politik di Indonesia: Tinjauan Sekilas pada Era Soekarno. In I. N. Bhakti, D. M. Mengko, \& S. N. Siregar (Eds.), Intelejen dan Politik Era Soekarno2 (pp. 1-22). LIPI Press.

Colijn, A. W. (1949, November, 29). Welkom voor S. Hamid. De Locomotief, 2.
Colijn, A. W. (1950, Januari, 18). TNI in Pontianak. De Locomotief, 4.

Darmadi, Y. (2017). 110 Tahun Dokter Mas Soedarso. Balai Pelestarian Nilai Budaya Kalimantan Barat, 2. https://www.pustakabpnbkalbar.org/berita/110-tahun-doktermas-soedarso

Feith, H. (2007). The Decline of Constitutional Democracy in Indonesia. Equinox.

Hasanudin. (2016). Poltik dan Perdagangan Kolonial Belanda di Pontianak. Patanjala: Jurnal Penelitian Sejarah Dan Budaya, 8(2), 203-218. https://doi.org/10.30959/patanjala.v8i2.7 3

Hatta, M. (2018). Mепијu Gerbang Kemerdekaan. Kompas Media.

Houbolt, J. (1950, Agustus, 18). Vervulling van Nationale aspiraties brengt politieke stabiliteit. Nieuwsblad Voor Indonesie, 2.

Houbolt, J. (1950, April 6). Commentare op Arrrestatie van Sultan Hamid II. Nieuwsblad Voor Indonesie, 1.

Huda, N. (2009). Otonomi Daerah: Filosofi, Sejarah Perkembangan, dan Problematika. Pustaka Pelajar.

Joel, H. (1949, November 26). Overdracht, concentratie en hulpverlening. Java Bode, 4.

Joel, H. (1950, Januari, 12). Daerah-hoofd West-Borneo. Java Bode, 2.

Joel, H. (1950, Maret, 10). Staking te Pontianak legt bedrijfsleven lam. Java Bode, 4.

Joel, H. (1950, Mei, 10). Tweehoeksconferentie begint 16 Mei. Java Bode, 1.

Kanumuyoso, B. (2020). Metode Sejarah. Direktorat PTLK, Dirjen Kebudayaan, Kementerian Pendidikan dan Kebudayaan.

Kanumuyoso, B., Brahmantyo, K., \& Irsyam. Tri Wahyuning M. (2020). Penulisan Sejarah (A. S. Rizal (ed.)). Direktorat PTLK, Dirjen Kebudayaan, Kementerian Pendidikan dan Kebudayaan. 
Klooster, W. S. (1949, September 20). De vlag in Kalimantan. Het Nieuwsblad, 4.

Klooster, W. S. (1950, Januari, 14). Hatta Bezoek Aan Pontianak. lHet Nieuwsblad, 4.

Kuntowijoyo. (2013). Pengantar Ilmu Sejarah. Tiara Wacana.

Leirissa, R. Z. (2006). Kekuatan Ketiga Dalam Perjuangan Kemerdekaan Indonesia. Pustaka Sejarah.

Listiana, D., Wijanarko, N. B., Prabowo, R. D., \& Ratmanto, A. (2015). Melawan Arus. Membaca Narasi Baru Sejarah Indonesia (Ara (ed.)). Atap Buku. https://www.academia.edu/35991217/TR OPE_BARU_SULTAN_HAMID_II_DI_ RANAH_POLITIK_LOKAL

Mangunwijaya, Y. (1999). Menuju Republik Indonesia Serika. PT. Gramedia Pustaka.

Mierop, A. H. F. (1949, Desember, 24). Delegatie naar Nederland. Nieuwe Courant, 4

Mierop, A. H. F. (1950, Mei, 20). Essentialia RI-grondwet en het goede van de RIS. Nieuwe Courant, 4.

Mierop, A. H. F. (1950, Maret, 15). Pontianak geisoleerd. Nieuwe Courant, 4.

Mierop, A. H. F. (1950, Mei, 10). WestBorneo. Nieuwe Courant, 4.

Nugraha, D. P. (2012). Partai Politik Lokal di Indonesia (Analisis Kedudukan Dan Fungsi Partai Politik Lokal 1955-2011). Universitas Indonesia.

Persatuan Djaksa-Djaksa Seluruh Indonesia (Persadja). (1955). Process Peristiwa Sultan Hamid II. Penerbit Djakarta.

Putro, W. S. (2018). Konferensi Inter-Indonesia Tahun 1949: Wujud Konsensus Nasional antara Republik Indonesia dengan Bijeenkomst voor Federaal Overleg. Jurnal Sejarah Citra Lekha, 3(1), 34. https://doi.org/10.14710/jscl.v3i1.17341

Rahmayani, A. (2013). Industri Keramik Tradisional Cina Di Sakkok, Singkawang 1933-2000. Patanjala: Jurnal Penelitian Sejarah Dan Budaya, 5(2), 217. https://doi.org/10.30959/patanjala.v5i2.1 33
Rinardi, H. (2012). Dari RIS Menjadi Negara RI: Perubahan Bentuk Negara Indonesia Pada Tahun 1950. MOZAIK: Jurnal Ilmu Humaniora, Vol. 12(2), 92-209.

Sekretariat Negara Republik Indonesia. (1985). 30 Tahun Indonesia Merdeka: 19501964. PT. Citra Lamtoro Agung Persada.

Soedarto. (1989). Naskah Sejarah Perjuangan Rakyat Kalimantan Barat 1908-1950. Pemerintah Daerah Tk.II Kalimantan Barat.

Soedarto., Adhisidharto, W., \& Sugeng. (1978). Sejarah Kebangkitan Nasional Daerah Kalimantan Barat. Departemen Pendidikan dan Kebudayaan.

Staf Semdam XII. (1970). Tandjungpura Berjuang: Sejarah Kodam XII/Tandjungpura. Pontianak. Yayasan Tanjungpura.

Tanasaldy, T. (2014). Regime Change and Ethnic Politics in Indonesia Dayak Politics of West Kalimantan. KITLV.

Teunis, A. (1950, Maret, 9). Staking in WestBorneo. De Locomotief, 4.

Teunis, A. (1950, April 18). West-Borneo is Opgeheven. De Locomotief, 1.

Turiman. (2013). Analisis Semiotika Hukum Terhadap Lambangan Negara Republik Indonesia. Jurnal Hukum Dan Pembangunan, 43(3). https://doi.org/http://dx.doi.org/10.21143/ jhp.vol43.no3.1495

Usman, S. D. (2018). Di Bawah Lambaian Sang Merah Putih: Kisah Revolusi Kalimantan Barat 1945-1950. Dewan Harian Daerah Badan Pembudayaan Kejuangan 45 Kalimantan Barat.

Utami, D. (2004). Kabinet Republik Indonesia Serikat (RIS) 20 Desember 1949-6 September 1950 [Universitas Sanata Dharma]. https://repository.usd.ac.id/25949/

Utami, S. R. (2018). Revolusi Kemerdekaan Indonesia 1945-1949. Derwati Press.

Vinsensius. (2015). Sultan Hamid II Berwajah Ganda Dalam Karier Politiknya di Indonesia [Universitas Sanata Dharma]. https://repository.usd.ac.id/2748/ 
Wajidi, W. (2015). Eksistensi Partai Indonesia Raya (Parindra) Di Kalimantan Selatan, 1935-1942. Patanjala: Jurnal Penelitian Sejarah Dan Budaya, 7(1), 17. https://doi.org/10.30959/patanjala.v7i1.8 0

Widayati, W. (2015). Sistem Parlemen Berdasarkan Konstitusi Indonesia. Masalah-Masalah Hukum, 44(4), 415. https://doi.org/10.14710/mmh.44.4.2015. 415-424

Yanis, M. (1998). Djampea: Novel Sejarah Perjuangan Rakyat Kalimantan Barat. Dewan Kesenian Kalimantan Barat dan Badan Penerbit Universitas Tanjungpura.

Zamzam, Z. (1950, Maret, 31). Residen buat Kalimantan Barat. Kalimantan Berdjuang, 1. 
Patanjala, ISSN 2085-9937 (print), ISSN: 2598-1242 (online) 